Kriz Dergisi 6 (2): 9-16

\title{
KORKU: SEBEPLERI, SONUÇLARI VE BAŞETME YOLLARI
}

\author{
Tülin GENçöz:
}

\section{OZZET}

Korku kişinin kendi düşüncelerinin sebep olduğu bir duygudur. Bu düşüncelerin içeriğinde "tehljke" olduğu için korku reaksiyonu verilir. Bu nedenle aynı durumla karşılaşan değişik kişiler, farklı dūşünceleri neticesinde farklı reaksiyonlar verebilirler. Ancak çoğu zaman korkuyu yaşayan kişiler bunun kendi düşüncelerinden kaynaklandığını bilmedikleri için etkili bir çözūm üretme yoluna gitmezler ve çaresizlik yaşayarak, korkularını kriz boyutlarına taşıyabilirler. Yaşanan bu krizler de kaçınma davranışlarını arttırarak hayattan zevk alma potansiyelini azaltırlar. Öte yandan, korku hissini yaratan ortamdaki düşüncelerini sorgulayan ve bu ortamdan kaçmayan kişiler, bu duygularını yenmeleri sonucunda hem önemli beceriler kazanırlar hem de kendilerine olan güven ve yeterlilik hislerinin artması gibi anlamlı gelişmeler gösterirler.

Anahtar Sözcükler: Korku, kaygı bozukluğu, kaçma, kaçınma, başetme yolları.

\section{Fear: Causes, Consequences, and Ways of Coping}

\section{SUMMARY}

Fear is an emotion that is a product of one's own thoughts. Due to the fact that the content of

* Öğretim Görevlisi, Ora Doğu Teknik Üniversitesi Psikoloji Bölūmü. these thoughts includes "danger", fear reaction is exhibited. Thus, different individuals who are exposed to similar situations may give different reactions as a result of their differences in thought. On the other hand, since usually people in fear do not know that their reactions are caused by their own thoughts, they do not look for an efficient coping style and consequently crisis is experienced, accompanied by feelings of helplessness. The experienced crisis may increase the number of avoidant acts and lead to a deprivation in the obtained pleasure in life. On the other side, those people who question their thoughts that are developed in fear evoking situation and who do not escape from these situations may reduce their fear, and in due course they gain some important skills and show significant improvements like increasing their selfesteem and self-efficacy.

Key Words: Fear, anxiety disorders, escape, avoidance, ways of coping.

Korku, içinde bulunduğumuz dunuma değil, bu durum için geliştirdiğimiz düşüncelerimize verdiğimiz bir reaksiyondur. Bu nedenle, korkuyu yenmek için kontrołün bizde olduğunu fark edip, korku hissi uyandıran düşünce tarzımızın doğruluğunu sorgulamamız gerekir. Bu sorgulama sonucu korktuğumuz ortamla yüzleşip, korkumuzu yenebilirsek bu bize hem yeni beceriler kazandıracak, hem de kendimize olan güvenimizi arttırarak mücadeleci bir kişilik geliştirmemize ơnemli katkılar sağlayacaktır. 
Bu derlemede de korkunun sebepleri, sonuçlanı ve profesyonel bir yardım almadan önce denenilebilecek bazı başetme yolları ele alınacaktır.

\section{Korkunun sebepleri:}

Korku tehlike düşüncesinin uyandırdığı duygusal bir reaksiyondur (Beck ve ark. 1987, Beck ve Clark 1988, Beck ve Emery 1985, Clark 1986, Clark ve ark 1989, Harrell ve ark 1981, Wickless ve Kirsch 1988). Korku ve kaygı içerikleri bakımından birbirlerine çok benzeyen kavramlar olmalarlnın yanısıra, kaygıda bu duyguyu meydana çıkaran durum kişi için çok açık değildir fakat kişi aşırı korku reaksiyonu verir. Başka bir psikolojik bozukluk olan depresyonla kıyaslandığında ise, depresyonda kayıp ve başarısızlık sonucunda kişi için kesinleşen düşünceler yer alırken (Watson ve Tellegen 1985), korku ve kaygı bozukluklartnda düşünceler, gerçekleşmemiş fakat muhtemel bir tehlikeye karşı geliştirilir (Ingram ve ark. 1987).

Bu bilgilerle tutarlı olarak Beck ve arkadaşlarıกın (1987) geliştirdiği, kişilerin çeşitli beklenti ve düşüncelerinj içeren "Biliş Tarama" (Cognitions Checklist) ölçümũ ile yapılan araştırmalarda kaygı bozuklư̆u olan kişilerin depresif kişilere kıyasla, ileriye yơnelïk tehlike beklentisi içeriğindeki dūşüncelerinin daha fazla olduğu bulunmuştur (Clark ve ark 1989, Steer ve ark. 1994).

Doğal olarak insanlar, tehlikeli olarak değerlendirclikleri durumlardan mümkün olduğu kadar uzak kalmak, өğer bu durumun içindelerse de kaçmak, kendini korumak isterter. Dolayısıyla korku içerdiği tehlike düşüncesi neticesinde, beraberinde korunma, kaçma davranışı getiren bir duygudur.

Kişilere korku reaksiyonunu neden verdikleri sorulduğgunda çoğu zaman rasyonel bir açıklama getiremezler, çünkü korku reaksiyonu durumdan değil durum için geliştiriten fikirlerden kaynaklanmaktadır. Bunun için şöyle bir örnek verilebilir, yılan seven ve sevmeyen iki insan aynı yılanı farklı şekillerde tarif edebilirler. Birisi yllanı incelenmeye değer, sevimli, ilginç bir canlı olarak görürken, diğeri aynı yılanı soğuk, sevimsiz, tehlikeli olarak tarif edebilir. Oysa ki, her iki kiși de aynı yılanla, aynı ortamda karşılaşmıştır. Buradan korku hissinin asında fikirlerimizden kaynaklandığı anlaşımaktadir.
Bilişsel teoriye göre, değişik bozukluklarda o bozukluğa has düşünce yapıları vardır (Beck ve Clark 1988). Bu nedenle bir çok araştırmacı değişik tipteki kaygı bozukluklarında temel olan düşünce yapılarını araştırmıştır. Goldstein ve Chambless'e (1978) göre agorafobinin temelinde "korkunun korkusu" ("fear of fear") dūșüncesi yatmakładır. Bu düşünce korku sonucu ortaya çıkan aşı! vücut reaksiyonlarından ve bunların neden olacağı sonuçlardan korkmak olarak açıklanabilir. Chambless ve Gracely'nin (1989) çalışmalarma göre ise, korkmaktan korkma, sadece agorafobi için değil panik bozukluğu, genel anksiyete bozukluğu, sosyal fobi, obsesif-kompalsif bozukluk gibi değişik kaygı bozukluğu türleri için ortak bir özelliktir. Clark (1986)da korkunun çok yoğun olarak yaşandığı panik ataklarını, fizyolojik reaksiyonların abartılı yorumlanmasıyla açıklamaktadır.

Görüldūğü gibi kaygı bozukluklannda kişinin durumu değerlendirme şekli, yani içinde bulunduğu durumun tehlikeli olduğuna ilişkin dūşünceleri önem kazanmaktadır. Örneğin, panik bozukluğu olan bir kişi için ufak bir kalp çarpıntısı, kalp krizi geçirmekte olduğunun bir kanıtı olarak değerlendirilebilir ve bu değerlendirme sonucu kişi panik atağı geçirebilir. Benzer bir şekilde, agorafobik bir kişi için "dişarıya çıkarsam heyecandan kalbim çok hızlı çarpar ve terlemeye başlarım, bunlar da kontrolümũ kaybedip bayılmama neden olabilir" tarzındaki düşünce, kişiyi dışarıya çıkmaktan alıkoyabilir. Öte yandan, kişi bu düşüncelerle dışarı çıkmayı denerse panik atak geçirebilir ve bu tecrübesiyle de, bir anlamda, düşüncelerinin doğruluğunu desteklemiş olur. Bu ōrnekte de görüldüğũ gibi, agorafobjnin temeli evden ayrılma ya da dışarı çıkma korkusu dḝil, panik atak geçirme korkusu ve bu atağın gerçek veya tahmin edilen sonuçları için duyulan korkudur.

Kişilerin olayları değerlendirme tarzları sosyal tobide de onemi bir rol oynamaktadır (Butler 1985). Sosyal fobik bir kişi korku sonucu ortaya çıkan somatik ve davranış semptomlarıni, durumun tehlikeli olduğuna dair bir kanıt olarak değerlendirir. Ömeğin yüzünün kızardığını hisseden bir sosyal fobik, diğerierinin kendisiyle alay ettiklerini düşünebilir. Bu tip olumsuz düşüncelere odaklanan bir kişinin performans düzeyinin düşmesi kaçınılmazdır. Performansının düştüğünü farkedince ise kişinin hareketleri donuklaşır ve doğallığını kaybeder, bu 
tavirları da etraftan sıcak tepki alma ihtimalini dūşürür. Sosyal fobide dikkatin olumsuz kaygı içerikli uyaranlara kayma ozelliği (Greenberg ve Beck 1989, Ingram ve ark. 1987) düşünüldüğünde, bu değerlendirmeler sonucu kişi performansının aşırı kötü olduğunu düşünür ve tüm bu süreç kısırdöngü halinde devam eder.

Görüldŭğũ gibi değişik kaygı bozukluklanı, değişik içerikli düşünce tarzları ile birbirlerinden ayrılmaktadir. Panik bozuklukta fizyolojik semptomlarin abartılı yorumlanması da bu dusşunncelerin temelini oluştururken, agorafobide muhtemel bir panik atağı sonucu yaşanabilecek kontrol kaybı, sosyal fobide ise diğerlerinin kişi ve kişinin performansı hakkındaki düşünceleri önem kazanmaktadır.

Duyduklarımız, gördüklerimiz, televizyon, sinema, tiyatro ve günlük konuşmalar yoluyla korkularımızın kaynağı olan düşūnceleri ister istemez geliştiririz. Bu nedenle korku reaksiyonunun gelişmesinde menfi bir olayın doğrudan kişinin başına gelmesinin yanısıra, çevremizden edindiğimiz bilgiler de aynı türden reaksiyonların verilmesine sebep olabilirler. Hayatımızda yılanla ilgili hiçbir olumsuz tecrübe yaşamamış olsak dahi, yllan görmeye tahammül edemeyebiliriz. Böylece fikirlerimizin doğruluğunu test etme şansını kendimize tanımamış oluruz. Yanlıs olup olmadığını test etmediğimiz fikirlerin sebep olduğu korku hissi ve bunun beraberinde gelen kaçma davranışı sonunda rahatladığımızda, sanki fikirlerimiz doğnuymuş gibi düşũnũrüz. Böylelikle korkularımız kuvvetlenerek devam eder.

Kuwvetli korkular kuvvetli kaçma davranışını da beraberinde getirir. Ancak, daha once de belirtildiği gibi, bu korkuların ardında içinde bulunulan durum için geliştirilen fikirler yer alır. Bu, korkuyu kriz derecesinde yaşayan birçok kişinin göz önüne almadığı bir bilgidir. Kişiler verdikleri duygusal reaksiyonları içinde bulundukları duruma bağlamaları neticesinde bu duyguyu yenmek için bir çaba sarfetme gereği duymazlar ve sıklıkla da düşünceleriyle duygularını desteklerler (Beck ve Emery 1985). Sôz konusu dūşünce-duygu kısır dōngüsünün krizle sonuçlanması ve kişinin çaresizlik yaşaması sık karşılaşılan bir durumdur. Çaresizlik yaşayan bir kişi, durumu kendi kontrolünde hissedemez ve bu durumdan kendi becerileriyle kurtulamayacağını düşünür (Abramson ve ark 1978). Burada yaşanılan çaresizlikte kişinin içinde bulunduğu durum için geliştirdiği atıflar önem kazanmaktadır. Girodo ve arkadaşlarına göre de (1981) fonksiyonel olmayan atıflar kaygı bozukluğunun ơnemli bir özelliğidir. Bu atıfların neden olduğu çaresiztik dūşüncesi ise kişinin yaşadığı krizin boyutlarını daha da arttırır çünkü kişi artık durumdan kaçmak veya durumu kabul etmeye çalışmaktan başka bir başetme yolu aramamaktadır.

Kişilerin kullandıkları başetme yollarına bakıldığında, iki temel yol olduğu görülmektedir, bunlar problemi çözmeye odakı başetme yolları ve duygusal rahatlamaya odaklı başetme yollarıdir (Folkman 1984). Problemi çözmeye odaklı başetme tarzı, direk olumsuz duyguyu yaşatan problemi azaltacak veya tamamen ortadan kaldıracak davranışlara yönelmeyi gerektirirken, duygusał rahatlamaya odaklı başetme tarzında kişi ya durumu herhangi bir çaba göstermeden kabul etmeye ya da bu duyguyu ortaya çıkaran ortamdan kaçmaya yönelir. Probleme odaklı tarzda doğrudan problemin çözümū amaçlanır. Duyguya odakiı başetme tarzında ise kişi problemin çözūmü için herhangi bir davranış geliştirmeden sadece duygusal rahatlamayı sağlama amaçlı yollara yönelmekte, bu tarz da kaçma-kaçınma davranışlarını kuvvetlendimektedir. Araştırmalar, kişilerin içerisinde bulunduklan problemli durumu kontrolleri altında olarak değerlendirdiklerinde problemi çözmeye odaklı başetme yolunu tercih ederken, kontrolleri dişında bir durumda olduklarını düşündüklerinde duygusal rahatlamaya odaklı başetme yołunu tercih ettiklerini göstermektedir (Folkman ve Lazarus 1980). Görüldüğü gibi kişinin içerisinde bulunduğu durum üzerinde hissettiği kontrol, tercih edilen başetme yolunda onemli bir rol oynamaktadır.

Söz konusu kontrolün hissedilmesinde en önemli nokta ise kişinin verdiği duygusal reaksiyonun içinde bulunduğu durumdan değii bu durum iç̧in geliştirdiği dūşüncelerinden kaynaklandığını anlamasidır. Bu kural tüm duygusal reaksiyonlar için geçerlidir, korku reaksiyonunda da sözü edilen düşüncenin içeriği tehlike üzerine kurulmuştur (Beck 1976. Beck ve Emery 1985). Araştırmalar kaygı bozukłuğu olan kişilerin iç kontrol algısında önemli bir düşüş olduğunu göstermektedir (Beck ve Emery 1985). Araştırmalar kaygı bozukluğu olan kişilerin iç kontrol algısında önemli bir düşüş̧ olduğunu göstermektedir (Beck ve Emery 1985; Cloitre ve ark 1992). Kontrol algısındaki bu dũşüş değişik korku türleri için farklı içerikler gősterebilir. 
Nitekim, panik bozukluğu olan kişiler "hastalık", "rahatsızlık" gibi kelimelere daha duyarlı iken, sosyal kaygısı olan kişilerin "eleştirilme", "küçūk görülme" gibi kelimelere daha duyartı oldukları bulunmuştur (Hope ve ark. 1990). Daha açık şekliyle, panik bozukluğu olan kişiler hastalık, rahatsızlık gibi konularda kontrolü kendilerinde hissetmezken, sosyal fobisi olan kişiler eleştirilme, küçük görülme gibi durumlarda kontrolün kendilerinde olmadığını düşünebilirler. Nitekim Cloitre ve arkadaşlarının (1992) çalıșmalarında hem panik bozukluğu olan kişiler hem de sosyal fobisi olan kişiler için iç kontrol algısı "normallere" kıyasla daha düşük bulunurken, dış kontrol algısında ozzellikle panik bozukluk için olayların rastgele şansa bağlı olarak geliştiği fikri, sosyal kaygı için ise olayların güçlü diğer kişiler tarafından belirlendiği fikri ağır basmaktadır. Gōrüldüğũ gibi değişik korku tipleri değiş̧ik türdeki tehlike düşünceleriyle (hastalık, diğerlerinin gōzünde değer kaybetme gibi) birbirinden ve "normal" davranışłardan ayırt edilebilmektedirler.

Olayların meydana gelmesinde kontrołün kişinin elinde olmadığı düşünncesi yukarıda da sözü edildiği gibi, kişilerin içerisinde bulundukları olumsuz duruma neden olan problemi doğrudan çözmeye yőnelmelerini engeltemektedir. Korkunun ortaya çıkışı ve devam edişine, yükseklik korkusu olan bir kişiyi örnek verecek olursak, bu kişi yüksek bir yere çıktığında "burası çok yüksek her an düşebilirim", "birazdan kontrolümü kaybedip bayılacağım", "işte hayatımın son anłarını yaşıyorum" gibi düşūnceleri neticesinde kalp atışlarında artış, terleme, titreme gibi fizyolojik reaksiyonlar gösterebilir. Artan bu fizyolojik reaksiyonlar çởunlukla kişi tarafından yukarıda örnekleri verilen düşüncelerin kuvvetlenerek devam etmesine ve daha da çeşitlenmesine sebep olur, bu da yaşanan korkuyu ve dolayısıyla da fizyolojik reaksiyonları daha da artırır. Bu kısır döngünün devamı neticesinde kişi olay üzerinde hiç bir hakimiyeti olmadığını düşünerek çareșizlik hisseder ve yaşanan korku artık bir kriz halini alır.

Görüldüğü gibi, korku kişilerin lçinde bulundukları durum için geliştirdikleri tehlike düşünceleriyle ortaya çıkan ve krizle sonuçlanabilen duygusal bir reaksiyondur. Ancak, çoğunlukla kişiler tarafından duruma verilen bir reaksiyon olarak deḡerlendirimesi sonucu, kişilerin bu durumu kontrol etme becerileri onemli ölçüde zayıflamakta ve kişiye çaresizlik yaşatmaktadır. Çaresizlik hissi uyandıran durumun kişi için önemi arttıkça yaşanan krizin de boyutu artabilecektir.

\section{Korkunun Sonuçlarn:}

Korku hissi oldukça rahatsız edici olduğu için, korkuyu hisseden kişiler bu hissi uyandıran nesne veya durumlardan mümkün olduğu kadar kaçmaya çalışırlar. Bu kaçma davranışı kişinin bu ortamı bir kez daha deǧerlendirme fırsatını, yani geliştirdiği fikiterinin gerçekliliğini gözden geçirme fırsatını kişiye tanımaz. Bunun neticesi olarak da kaçmakaçınma davranışı kişiyi rahatlattı̆̆ı için, kişi "bir kez daha bu tehlikeli durumdan kurtuldum" yorumunu yaparak, bu durumun tehlikeli olup oimadığtnı test etme şansını kendisine tanımadan bu düşūncesini kuvvetlendirmiş olur.

Korkuya neden olan durumdan mümkün olduğunca uzak kalmaya başlandığında insan, hareket serbestliğini kendi kendine kısıttar. Bu kısıtlanma da, günlük hayatta yerine getirmek zorunda olduğumuz görevierimizi, hayatı zengin bir şekilde yaşayarak tecrübe edebileceğimiz olumlu duyguları engeller. Tüm bu süreç için şöyle bir ömek verilebilir, değişik kişilerle tanışıp beğenilemeyeceğini ve eleştirilere maruz kalacağını düşünen bir genç, davet edildiği partiye orada yaşayacağı kaygı seviyesinin yūksekliğini düşünerek gitmemeyi tercih edebilir. Bu karar söz konusu genci rahatlatacaktır, ancak orada bulunan kişilerin onu gerçekten eleştirip eleştirmeyeceğini hiç test etmediği için bu sorunun doğru cevabını bilemeyecek ve hep kötümser bakış açısıyla "ya olursa?" diyerek kaçma-kaçınma tarzını sürdürecektir. Kısa vadedeki bu rahatlama, uzun vadede söz konusu gencin yaşıtlarından ve bir çok sosyal ortamda yaşayabileceği güzel duygulardan uzak kalmasına neden olabilecektir. Bu tür kaçma-kaçınma tercihleri üst-üste geldikçe de kişilenin bu ortamlarda geliştirmesi beklenen sosyal becerileri geliştiremeyecek ve zaman ilerledikçe bu girişim gitgide daha da zorlaşacaktır. Bunun sonucu da kişinin yalnızlık ve belki yine çaresizlik hissederek hayatı anlamsız, kendisini değersiz, geleceği ise ümitsiz olarak değerlendirmesine kadar uzanabilecektir. Beck'in (1976) olumsuz üçlü adınt verdiği bu düşünce tarzı, söz konusu kişinin depresyona girmesine de sebep olabilecektir.

Görüldüğü gibi korkuyu kriz derecesinde yaşayan kişiler, çoğunlukla bu duyguyu ortaya çıaran ortamdan mümkün olan en kısa sürede kaçmayı ve hatta belki bu tip ortamlara hiç girmemeyi tercih et- 
mektedirler. Bu kaçma ve kaçınmaya dayalı hayat tarzında kişi kriz boyutunda bir korku yaşamayacağı için tercih ettiği bu çözūmün en güvenli ve sağlam yol olduğunu düşünebilit. Oysa ki problemlerini kaçma ve kaçınma tarzı ile çözerek yaşamayı tercih eden bir kişi, kendisi için önemli ve zevkli olabilecek bir çok faaliyeti de yaşama intimalini kısıtlamış olacaktır. Bu kısıttamanın yanı sıra, korkudan kaçmayı karakter haline getiren bir kişi bir çok beceriyi geliştirme fırsatını da kaçıracak ve bunun neticesinde de problemli olayların üstesinden gelme gücünü de çoğu zaman kendisinde bulamayacaktır. Bu da geliştirdiği korkudan kaçmaya dayalı karakteri daha da kuwetlendirecektir.

Dolayısıyla, korkularımız kendimize verdiğimiz değerin de düşmesine sebep olabilirler. Kendimize verdiğimiz değer, günlük olaylar karşısında gösterdiğimiz performansın değerlendirilmesiyle ortaya çıar. Korkular nedeniyle bazı durumlardan uzak durmak bu degerlendirmenin neticesini olumsuz yönde etkileyecektir. Yani bir anlannda geliştirdiğimiz fikirler bizi daha dar bir dünyaya hapsederken, kendimize verdiğimiz değerin düşmesini de beraberinde getirecektir.

\section{Korkuyla Başetme Yollan:}

Yukarıda ele alındığı gibi korku, çoğu kez asında kendi kendimize geliştirdiğimiz flkirlere verilen bir reaksiyondur. Dolayısıyla korkuyla başedilmesi amaçlandığında bu fikirlerimizin doğruluğunun test edilmesi onemli bir adım olacaktır. Ancak, bu fikirlerin ilk test edilişlerinde korku seviyesinin yüksekliği kişilerin etkili bir fikir değerlendirmesi yapmaları$\mathrm{n} 1$ engelleyebilir. Bu nedenle korku uyandıran durumiardan kaçmama kararı alındığında, kişilerin kullanacakları rahatlama teknikleri önemli bir rol oynayacaktır. Korkuyu yenme yolunda atılacak ilk adımlar oldukça önemlidir, çünkü kişi ilk defa cesaretle korkuyu meydana getiren fikirlerini test etmeye ve bu durumla yüzleşmeye karar vermiştir. Kişinin cesaretini topladığı bu ilk tecrübesinde, kendine olan gũvenini, "ben bunu yapabilirim", "heyecanlansam da bunun üstesinden geleceğim" gibi destekleyici dūşüncelerle artırması ve olumsuz dūşüncelerini durdurmaya çalışması yararlı olacaktır. Ayrıca gerekiyorsa, bu durum karşısında korku hissini yaşamayan bir kişiyle beraber veya önce onu gözleyerek bu ilk tecrübesini yaşamast bu tecrübenin olumlu sonuçłanmasında ónemli bir rol oynayabilecektir.
Bu ilk tecrübelerin başarıyla sonuçlandırılmasının önemi de çok būyūktür. Mesela, kapalı bir yerde kalma korkusu olan bir kişi mümkün olduğunca kapalı yerlerden kaçacaktır. Bu durumda bu kişi yüksek bir yere çıkarken asansör kullanmamaya veya oraya hiç gitmemeye gayret gōsterecektir ve bu korkunun arkasindaki fikirleri test etme şansını kendisine tanımayacaktır. Ancak bu kişi korkuyu yenmeye karar verdiğinde yaşayacağı ilk tecrübe oldukça önemlidir. Mesela cesaretle asansöre binip, asansör hareket eder-etmez aşın korkusu nedeniyle vazgeçip birinci katta korkuyla asansörden inerse bu tecrübe kendisinde var olan kapalı yerde kalma korkusunu bir kez daha kuwvetlendirecek ve asansörün korku duyulacak bir yer olduğu ile ilgili fikirleri yine destek bulacaktir. Bu nedenle özellikle bu ilk tecrübelerde, korku düzeyi düşünceye kadar, korkutulan ortamda kalmayi becerebilmek çok önemli bir adım olacaktır. Bu amaçla korkuyu yenme yolundaki ilk adımlarda kişide en az korku uyandiran davranışla başlamak ve daha sonra yavaş yavaş ufak basamaklar halinde gerçekten korkulan durumu tecrübe etmek yararlı olacaktır. Mesela asansör ömeğinde kişi önce rahat bir şekilde asansőrü çağırma düğmesine basmayı, daha sonraki günlerde sırasıyla asansörün kapısını açmayı, asansơ̈rün kapısını açıp binip-inmeyi, asansőrūn kapısını açıp-binip çıkacağı katın düğmesine basıp inmeyi ve son olarak da asansörü yukarı bir kata çıkmak için kullanmayı tecrübe edebilir. Kişi bu tecrübelerini korkusuna yenilmeden yaşayabilirse eski fikirleri yerine, aynı durum için daha uyumlu yeni fikirler geliştirebllecektir.

Korkuyla başetme sürecinde diğer önemli bir etkende, korku uyandıran olaylarn üstesinden gelebilecek becerilerin henüz öğrenilmemiş olmasıdır (Beidel ve ark. 1985). llk ónceleri nötr olan bir durum beceri eksikliği nedeniyle başarısızıkla sonuçlandığında kişi bu durumdan uzak kalmayı isteyecek böylece durumla başa çıkabilmek için beceri geliştime fırsatlarını kendisine tanımamış olacaktır. Topluluk içinde konuşmaktan korkan ve bundan kaçan bir öğrenci, ilk once kendisini ifade etme becerisini geliştirmeli, daha sonra da bu temel becensini çeşiti topluluklarda tecrübe ederek geliş̧tirmelidir. Bunun için öncelikle kendisini daha rahat hissettiği ortamları seçerek kendisine olan güveninin de kuwetlenmesiyle, bu becerisini zamanla diğer ortamlara taşıması tavsiye edilebilecek bir yoldur. 
Kişiler korkulanın yenmek için çeşitli yollar deneyebilirler. Tercih edilen başetme yollar durumdan duruma olduğu gibi kişiden kişiye de değişebilir. Doğal olarak herkes kendi tarzı ve becerileri doğrultusunda problemlerine çözüm arar. Bu nedenle kişilerin ortaya çłkardığı çözümleri "doğru" ya da "yanklş" olarak yargılayamayız. Ancak, kullanilan başetme yolunun "etkili" ya da "etkisiz" olduğu veya "başarilı" ya da "başarısız" olduğu yorumunu sonuca ve kişiyi ne kadar rahatlattığına bakarak yapabiliriz. Bütün bunlardan dolayı korku yaşayan kişilerin, aktif bir rol alarak duruma kendi istekleri ve becerileri doğrultusunda çözüm arama gayretine girmelerini baş etme sürecindeki en önemli adım olarak görebilitiz. Her zaman başkalarının kullandığı veya tavsiye ettiği çözüm yolu bizim için en etkili/başarılı çözüm yolu olmayabileceği gibi, aklımıza gelen ilk çözüm de en etkili/ başarılı çözüm olmayabilir. Problemlere çözüm ararken çeşitli çözüm yollarını değerlendirmenin onemi büyũktür; bunun için kişi esnek düşünmeli ve değişik çözüm yolları aramaya gönūllū olmalıdır. Tabii, çözüm yolu aramaya geçmeden önce kişi problemini açık bir şekilde tanımlamalı ve istediği sonuca da bu tanımda yer vermelidir. Problemin tanımında soru cümlesi kullanıldığında problem açık olarak tanımlanabileceği gibi istenilen sonuç da ortaya çıacaktır. Ömeğin; "Yeterince cesaretli bir insan değilim" yerine "Daha cesaretil bir insan olmak için ne yapmalıyım?" sorusu sorulduğunda istenilen sonuç ortaya daha açık bir şekilde çıkacaktır. Ancak, bu ömekte de kullanılan cesaret sözcüguünün kişi için ne anlama geldiğinin açıklanması gerekit. Böylece ulaşıımak istenen sonuç çok açık bir şekilde kendisini gösterecektir.

Problemi tanımlayan sorunun doğru ve eksiksiz sorulması problem çözme becerisinin gelişmesinde onnemli bir rol oynamaktadır. D'Zurilla ve Goldfried'e göre (1971) problem çôzme becerisi beş basamaklı bir süreçtir. Birinci basamak problemin tanımıdır. Bu basamakta problem, istenilen sonucun da açık olacağı bir şekilde tanımlanır. Bu tanım içerisindeki soyut kavramlara da kişi tarafından açıklık getirilmesi önemlidir. Íkinci basamak altematif çözümlerin belirlenmesi basamağıdır. Bu basamakta kişi tanımladığı problem için akla gelebilecek her türlü çözūmü, hertangi bir kısıtlama olmaksızın düşünmelidir. Üçüncū basamak, alternatif çözümlerin değerlendirilmesi aşamasıdır. Bu basamakta kişi belirlediği alternatif çözümlerin so- nuçlarını dūşünür ve bunların problemin çőzümündeki etkisini, kendi becerileri ve kişiliğine uygunluğunu da dikkate alarak değerlendirir. Dördūncū basamak karar verme basamağıdır, burada kişi tüm değerlendirmeleri sonucu bir başetme yolunu seçer ve uygulamaya koyar. Son olarak da istenilen sonuç tam olarak eide edilemezse, tüm basamaklar yeniden gözden geçirilerek bir başka başetme yolu denenir.

Görüldũğủ gibi problem çözme becerisi problemin tanımıyla başlayan beş basamaklı bir süreçtir. Bu süreçte ilk basamak önemlj bir rol oynamaktadır. Çünkü bu basamaktaki eksiklik ve yanlışlıklar diğer basamakları da etkileyecektir. Bunun için şöyle bir örnek verilebilir, eşiyle dayak ve/veya aldatmaya dayalı problemler yaşayan ve eve gitmekten korkan bir kimse problemin tanımında "Eve rahatlıkła gidebilmek için ne yapmalıyım?", "Eşimden dayak yememek için ne yapmalıyım?" veya "Eşimin beni aldatmarnası için ne yapmalıyım?" seklinde sorular getirirse, bu sorular problemin çōzümünde çok dar bir alanın taranması ile sonuçlanacak ve belki de asil arzulanan ve elde etmek istenen sonuç gözden kaçırılabilecektir. Bu iki dunumda da kişi "Daha mutlu ve huzurtu olabilmek için ne yapmalıyım?" gibi daha genel ve asıl ulaşımak istenen nihayi hedefi de belirten bir soru sorarsa, alternatif çōzümlerin üretilmesi aşamasında, içinde bulunduğu ortamı ve imkanlarını çok daha kapsamı bir şekilde tarayacaktır. Bu taramanın sonucunda da, dar bakış açısıyla kolaylıkla gözden kaçırabileceği, durumla, kişiliğiyle ve istekleriyle uyumlu bir çok çözüm yollarını bulabilecektir. Bu nedenle, problemin tanımlandığı ve alternatif çözümlerin beliriendiği ilk iki aşamada esnek bakış açısı, problemin başarılı çözümünde oldukça önemli bir rol oynamaktadir.

Kullandığı herhangi bir başetme yolu neticesinde, eskiden korku uyandiran bir durum karşısında, kontrolü ele alabilen ve bu korkusunu yenebilen kişi, yani bir anlamda korkudan kaçma yerine üzerine giden ve onu yenen kişi kendisine olan güvenin artması, diğer olaylara daha cesaretle yaklaşması ve belki de en önemlisi olaylar karşısında kontrolū elinde hissetmesi gibi bir çok kazanç elde edecektir. Bu nedenle, mücadeleci bir yaklaşımla, problemi çözmeye odaklı başetme yollarını deneyerek, yaşanan korkuyu kişinin kendissini geliştirebileceği bir fırsat olarak değerlendirmesi ve bu duygudan 
kaçmadan onu yenmeye çalışması, zamanla kişide yeterlilik hissini geliştirecek ve becerilerini artıracaktır. Bu olayların çeşitliliği neticesinde de artık kendisine güvenen kişi, olaylar karşısındaki iç kontrolünü kaybetmeyecek ve mücadeleci bir yaklaşımla, bir başka deyişle çaresizlik yaşamadan doğrudan problemi çözmeyi hedefleyen başetme yollart arayabilecektir.

\section{SONUÇ}

Korku karşılaştı̆̆ımız nesneye veya içerisinde bulunduğumuz duruma değil, kendi düşüncelerimize verdiğimiz bir reaksiyondur. Bu nedenle, korkuyu yenmek için herhangi bir dış gũcün durumu düzeltmesini beklemek veya bu ortamdan kaçmak yerine, korkuya neden olan düşūncemizi bulup. onu test etmek korkumuzu yenmemizde önemil bir adım olacaktır. Ancak, düşüncelerimizi test etmeye veya bir başka deyişle korktuğumuz durumla karşılaşmaya karar verdiğimizde olumsuz düşüncelerimizi durdumak, ufak basamaklar halinde ilerlemek, gerekiyorsa problem çözme tekniklerinden yararlanmak ve durumun çōzümü için gerekli becerilerimizi geliştirmek, bu tecrūbelerin başarıyla sonuçlanmasında önemli bir rol oynayacaktır. Başarıyla sonuçlanan bu tecrübeler neticesinde de korku hissimizi yenmenin yanısıra kendimize güven ve yeterlilik duygularındaki artma ile beraber mücadeleci bir kişilik tarzı geliştirme yolunda önemli ilerlemelerde sağlamış oluruz. Bu nedenle gerekli donanımı sağladiktan sonra korkudan kaçmak yerine korkunun üzerine gitmek, birçok olumlu gelişim için bir fırsat olarak da değertendirilebilir.

Dolayısıyla korkan bir kişiye sosyal destek vermek durumunda olan kişi, geneide yapıldığı gibi o kişinin korktuğu durumla karşılaşmasını engellemek yerine, kişinin bu korkuyla mücadele etmesini sağlayabilecek donanımlarını araştırmaya çalışması ve bunun için karşısınndaki kişiyi gönüllendirmesi, aynı zamanda durumun kontrol edilebilirliğini göstermesi, hem problemin çözümünde hem de olumlu kişilik özellikleninin geliştirilmesinde oldukça önemli bir rol oynayacaktır.

\section{KAYNAKLAR}

Abramson LY, Seligman MEP, Teasdale J (1978) Leamed helplessness in humans: Critique and refomulation. Journal of Abnormal Psychology, 87: 49-74.

Beck AT (1976) Cognitive therapy and emotional disorders. New York: New American Library.

Beck AT, Brown G, Steer RA ve ark (1987) Differentiating anxiety and depression: $A$ test of the cognitive content-specificity hypothesis. Journal of Abnomal Psychology, 96: 179-183.

Beck AT, Clark DA (1988) Anxiety and depression: An information processing perspective. Anxiety Research, 1: 23-26.

Beck AT, Emery G (1985) Anxiety disorders and phobias: A cognitive perspective. New York: Basic Books.

Beidel DC- Tumer SM, Dancu CV (1985) Physiological, cognitive and behavioral aspects of social anxiety. Behaviour Research and Therapy, 23: 109-117.

Butler $G$ (1985) Exposure as a treatment for social phobia: Some instructive difficulties. Behaviour Research and Therapy, 23: 651-657.

Chambless DL, Gracely EJ (1989) Fear of fear and the anxiety disorders. Cognitive Therapy and Research, 13: $9-20$.
Clark DA (1986) Cognitive-affective interaction: $A$ test of the "specificity" and "generality" hypotheses. Cognitive Therapy and Research, 10: 607-623.

Clark DA, Beck TA, Brown G (1989) Cognitive mediation in general psychiatric outpatients: A test of the content specificity hypothesis. Joumal of Personality and Social Pschology, 56: 958-964.

Clark DM (1986) A cognitive approach to panic. Behavior Research and Therapy, 24: 461-470.

Cloitre M, Heimberg RG, Liebowitz MR ve ark (1992) Perceptions of control in panic disorder and social phobia. Cognitive Therapy and Research, 16: 569-577.

D'Zurilla TJ, Goldfried MR (1971) Problem solving and behavior modification. Joumal of Abnormal Psychology, 78: 197-226.

Folkman $S$ (1984) Personal control and stress and coping processes: A theoretical analysis. Joumal of Personality and Social Psychology, 46: 839-852.

Folkman S, Lazarus RS (1980). An analysis of coping in a middleaged community sample. Journal of Health and Social Behavior, 21: 219-239.

Girodo M, Dotzenroth SE, Stein SJ (1981) Causal attribution bias in shy males: Implications for self-esteem and self-confidence. Cognitive Therapy and Research, 5: $325-338$. 
Goldstein A, Chambless D (1978). A reanalysis of agoraphobia. Behavior Therapy, 9: 47-59.

Greenterg MS, Beck AT (1989) Depression versus anxiety: A test of the content-specificity hypothesis. Journal of Abnomal Psychology, 98:9-13.

Harrell T, Chambless D, Calhoun J (1981) Correlational relationships between self-statements and effective states. Cognivite Therapy and Research, 5: 159-173.

Hope DA, Rapee RM, Heimberg RG ve ark (1990) Representations of self in social phobia: Vulnerability to social treat. Cognitive Therapy and Research, 14: 117189.
Ingram RE, Kendall, PC, Smith TW ve ark (1987) Cognitive specificity in emotional disorders. Joumal of Personality and Social Psychology, 53: 734-742.

Steer RA, Beck AT, Clark DA ve ark. (1994) Psychometric properties of the Cognition Checklist with psychiatric outpatients and university students. Psychological Assessment, 6: 67-70.

Watson D, Tellegen A (1985) Toward a consensual structure of mood. Psychological Bulletin, 98: 219-235.

Wickless C, Kirsch I (1988) Cognitive correlates of anger, anxiety, and sadiness. Cognitive Therapy and $\mathrm{He}-$ search, 12: 367-377. 